\title{
An Arts-Based Instructional Model for Student Creativity in Engineering Design
}

\author{
https://doi.org/10.3991/ijep.v7i1.6335 \\ B. LaDuca \\ University of Dayton, Dayton, OH, U.S.A. \\ bladuca1@udayton.edu \\ A. Ausdenmoore \\ University of Dayton, Dayton, OH, U.S.A. \\ aausdenmoore1@udayton.ed \\ J. Katz-Buonincontro \\ Drexel University, Philadelphia, PA, U.S.A. \\ jlk333@drexel.edu \\ K.P. Hallinan \\ University of Dayton, Dayton, OH, U.S.A. \\ kevin.hallinan@udayton.edu \\ K.L. Marshall \\ University of Dayton, Dayton, OH, U.S.A. \\ marshallk4 eudayton.edu
}

\begin{abstract}
Over the past twenty years, nearly all job growth in the United States has emerged from new companies and organizations with assumedly innovative products, services, and practices. Yet, the nurturing of student creative thinking and problem solving is infrequent in engineering education. Inherent to developing these creativity skills and attributes is the need to be exposed to difference - in people and environment. Engineering education rarely offers such opportunities. Additionally, engineering students are rarely presented opportunities to develop designs responding to real human problems. This paper puts forth a new instructional model to address these needs by utilizing arts processes and practices as catalysts for both creativity development in students and transdisciplinary collaboration on problems addressing deep human needs. This model is premised on the substantiated role of the arts in developing creativity and growing understanding of the human condition.

This art-based instructional model was piloted as exploratory pedagogical research during the summers of 2015 and 2016 as a partnership between the Institute of Applied Creativity for Transformation (IACT) and the School of Engineering at the University of Dayton. In each year, this program supported twelve student interns from engineering, business, science, the arts, and the humanities to develop innovative technologies and services meeting client needs. Student growth in creative problem-solving and transdisciplinary collaboration,
\end{abstract}


as well as the success of the completed innovation technology prototype were assessed by the project mentors and participating students via survey evaluations and narrative responses. The assessment results revealed substantial student growth in student creativity and transdisciplinary collaboration and a remarkably strong evaluation of the success of the students' innovations. Also realized for all students was a transformation in their perception of their place in the world as professionals post-graduation.

Keywords-Engineering creativity, transdisciplinary collaboration, arts, vocation

\section{Background: Infusing Creativity into STEM Pedagogy}

Richard Florida's 2001 pioneering book, The Rise of the Creative Class, attributed nearly all job growth in the United States over a 20 year period prior to the writing of his book, to the creatives; namely engineers, scientists, artists, entrepreneurs, etc... [1]. Other recent research supports this perspective. For example, the Kauffman Foundation found that between 1988 and 2012, companies more than five years old eliminated more jobs than they created in all but eight of those years. New and young companies were seen as nearly the sole source of job creation in the American economy. Additionally, these firms were recognized for their contribution to economic dynamism by injecting competition into markets and spurring innovation [2].

So, if the creative class drives the economy, it is essential to understand first what is meant by creativity and then how universities are helping to nurture growth in this quality. Numerous definitions have been posed. Sternberg lists sixty-one different definitions from a multitude of viewpoints including those of behavioral psychology, social psychology, cognitive science, philosophy, design research, innovation, and many others [3]. Broadly defined, 'creativity is the interaction among aptitude, process, and environment by which an individual or group produces a perceptible product that is both novel and useful as defined within a social context' [4]. A simpler definition of creativity is the ability to generate new ideas or new associations between existing ideas. Creativity is further associated with: a willingness to take chances; an ability to make unique connections between ideas; flexibility and imagination; a willingness to question normal approaches; and inquisitiveness and intuitiveness [5].

So, how are universities doing in nurturing growth in creativity? A 2015 survey of employers sponsored by the American Association of Colleges says "not very good." The survey findings showed that potential employers believed that only one-quarter of graduates from all disciplines were both creative and had acceptable critical thinking and problems solving skills. They also showed that only $18 \%$ of employers felt that students were prepared to work with people from different backgrounds, despite the fact that $96 \%$ of employers felt that students should have to solve problems with peers whose views are different than theirs [6]. 
Other research has shown that this dearth of creativity in students isn't uniform throughout the university. Zare's 2011 study of 160 engineering and arts students showed significant difference in creativity; with artists exhibiting greater levels of creativity than engineers [7]. Similarly, Charyton and Snelbecker measured creativity differences between 105 engineering and 100 music students via six different creativity measures. Their results indicated that musicIACTs scored higher in general and artistic creativity, with no significant differences in scientific creativity. Gender, age, and specialization within major yielded no significant differences [8].

Ragusa's research probed more deeply to assess where and how engineering student creativity flourishes and where it fails. She developed a new instrument to measure engineering students' creativity and tested the instrument at fourteen universities worldwide. Her analysis established an overall score for engineering students of 3.12/4.0, with scores for graduate students slightly higher than for undergraduate students. Her index scores were highest relative to disciplined imagination (3.5 undergrad/3.6 grad) and lowest for initiative (2.75/3.05), inquisitiveness (2.82/3.07), and self-confidence $(2.87 / 2.81)$ [9].

These assessments show significant room for improvement. But, growth in creativity skills among engineering students is simply not recognized as important. The ABET EC 2000 required outcomes don't address the maxims needed to nurture creative development, including: fostering inquisitiveness or open-mindedness, helping students become comfortable with ambiguity, providing continuous practice of ideation, encouraging students to search for multiple answers, and allowing students to take risks, fail, or have ownership of the education they wish to receive, among others. A 2007 study by Kazerounian and Foley of engineering programs relative to the place of these maxims in engineering curricula, as well as the possibility of rewarding creativity, found that virtually no university addressed these in the education of engineering students [5].

But, the National Academy of Engineering in its 2004 report The Engineer of 2020: Visions of Engineering in the New Century acknowledges that given the growing scope of the challenges to humanity ahead and the complexity and diversity of the technologies of the 21 st century, the importance of creativity as a quality of engineers will increasingly be important. The report also emphasized that this creativity necessarily requires synthesis of knowledge from multiple disciplines [10].

So, how might growth in creativity be fostered in engineering education? Hall and Johnson in a 2009 Harvard Business Review have suggested that the increasing standardization of processes throughout all business and society isn't appropriate if there is high variability in potential solutions and for nascent or broken processes (and assumedly products or services). Many situations require "judgement-based work" and responsiveness to changeable environments and when stakeholders value distinctive or unique output [11]. This type of environment can require quick thinking and creativity and a true understanding of individual needs and desires. Engineering education has certainly exploited standardization of processes in design, experimentation, problem-solving, etc... but arguably has not prepared graduates capable of this type of responsiveness and ability to understand the value of diverse perspectives in design processes. 
Further, the differences in creativity between arts and engineering students noted by Zare [7] and Ragusa [9] suggest that educational practices present in the arts might be looked at to help inform growth in creativity and creative problem solving in engineering students. All of the maxims required to foster creativity posed by Kazerounian and Foley described above are integral to arts education and practice. As Styhre and Eriksson noted in 2008, "Bring in the arts and get the creativity for free." Their study analyzed the impact of an Artists in Residence project in Swedish industries. Their results indicated that the presence of an artist on-site affected modestly the creativity of the employees who were able to observe and interact with the artist [12]. However, arts participation, however, doesn't necessarily render creativity development. Furnham et al., for example, found that the only correlation between arts participation and creativity scores were on self-reported data of creativity and creative success [13]. A follow-the-leader arts approach doesn't foster creativity development. Rather, art directed toward the creation of something original and new appears to do so.

Benefits of arts processes done right are numerous. Arts integration into STEM activities has seen significant advance in K-12 education. It has been strongly demonstrated to improve long-term retention of scientific knowledge [14] [15]. The speculation is that when students see, feel, and/or hear relative to a scientific topic, their cognition of the topic improves. Katz-Buonincontro showed that artistic experiences create new opportunities for learning how to solve problems creatively [16]. KatzBuonincontro et al. also showed that participating in unfamiliar art settings can help students with little to no art background build a foundation of aesthetic awareness. In turn, this can transfer to their work in other domains like engineering to develop a new intentional awareness about one's work, as well as an increased intensity to provide meaning for the consumer or end-user [17]. Some art experiences also provide students with the opportunity to amplify the emotional qualities of a problem, thus enabling students to sort out, select and optimize solutions to the problem. Heightened emotion can help foster collective idea generation in arts-based courses, before rushing prematurely to a "band-aid" solution. Lastly, Russell and Hutzell found that not only did collaborative art projects promote social and emotional learning, they also brought different people together [18].

Gnezda outlines the cognitive stages of the art creative process. This process ultimately begins with the search for something original. There must be some desire by a person to create. This search can be constrained by talent, interest, resource availability; but it is clear that the less constraint, the more opportunity for novelty. This search process needs time and maybe triggers. For some, novel ideas can come quickly; for others, not at all. Triggers are valuable. Seeing unrelated things can spur novel ideas. Ultimately, this search can realize the "Aha" moment, when a great idea can emerge. An artist can then proceed down an initial path, rendering their art. But, the path for art isn't linear. There is a process of continuous internal and external challenge to what is being created. In fact, if the challenges are external, the artist can experience dislocation, enabling the emergence of drastically different ideas [19].

Many arts processes and habits are foreign to the training of engineers and engineering education, such as some describe by Costa and Kallick. These include habits 
like "listening to others with understanding and empathy, thinking interdependently, thinking critically about others' ideas, gathering data through all senses, responding with wonderment and awe, being flexible, and taking responsible risks." The arts demand that artists listen to others, to empathize with and to understand their points of view. As a result, they are able to value the diverse perspectives of others. They gently attend to another person demonstrating their understanding of and empathy for an idea or feeling by paraphrasing it accurately, building upon it, clarifying it, or giving an example of it. With empathetic relationships established, artists are able to think interdependently. This interdependence they note is essential for bringing needed diverse perspectives to problem-solving. No one has access to all the data needed to make critical decisions; no one person can consider as many alternatives as several people can. Interdependence requires the ability to justify ideas and to test the feasibility of solution strategies on others. It also requires the development of a willingness and openness to accept critical feedback. Through this interaction the group and the individual continue to grow. Being open to criticism also requires a willingness to provide criticism; to continuously ask questions related to "What", "How", "Why", "Who", and "What if". With empathy for others, an artist seeks to provide critique of others in order to help them and the ideas improve. Interdependence also requires flexibility in order to consider alternative points of view or deal with several sources of information simultaneously [20].

Arts habits require an individual to see the world with wonderment and awe, and in so doing that individual is open to observations from the world around them. Moreover, artists ideally understand that all information gets into the brain through the sensory pathways: gustatory, olfactory, tactile, kinesthetic, auditory, and visual. If sensory pathways are open, alert, and acute it is possible to absorb more information from the environment. Artists are inherently curious, and as a result are continuously seeking out new problems to solve for themselves and to submit to others. Finally, artists' minds are open to change based on criticism, additional information or reasoning, which contradicts their beliefs. Flexibility of mind is essential for working with social diversity, enabling an individual to recognize the wholeness and distinctness of other people's ways of experiencing and making meaning. Further, flexibility is integrally linked to risk-taking [20].

Finally, Hall and Allen strongly strongly suggest that arts processes and habits include a willingness to take risks with permission to fail, dynamism and adaptability. Additionally, they suggest that the habit of artistic expression isn't a Powerpoint file or a technical report. Artistic expression can convey emotions and ideas in creative work, and include performances front of audiences. This type of expression evokes not only intellectual understanding but an emotional response in audiences [11].

Despite the obvious value from arts processes in learning, there are few examples of arts integration into engineering. The most notable is MIT's Center for Art, Science $\&$ Technology (CAST). Since its founding in 2012, MIT's program has given rise to some interesting experiments aiming to link engineering to the arts. For example, a highly multidisciplinary course called Mechanical Invention Through Computation was co-taught by a visiting artist and professors from Computer Science and Artificial Intelligence Laboratory (CSAIL), building upon traditional methods of invention 
using new computational tools [21]. A number of other technology-arts projects have rendered technology-enabled art works [8]. While such efforts are pioneering, they are certainly not institutionally transformative in regard to education.

\section{Institutional Context}

\subsection{University of Dayton Institute of Applied Creativity for Transformation (IACT)}

IACT was established in 2015 to empower students with the ability to confidently develop the imaginative and creative skills necessary for 'humanity-centered' innovation; e.g., innovation that enables humans to flourish, while impacting today's innovative and global workforce. Central to IACT is the use of practices and processes employed across the spectrum of arts, from sculpture to music to culinary to performance, to creative writing, installation art, theatrical set design, and more. The Institute was developed via two years of cross-campus collaboration that led to the establishment of the IACT Collective of Educators - a body of faculty, staff, alumni and regional creatives whose expertise and vocations are partnered to develop foundational curriculum and creative design. The inclusion of staff and alumni as equal contributors to faculty in the collective was especially important in broadening the diversity of ideas of the Collective in all ways. The IACT White Box Gallery hosts site-specific installations that bring the curriculum to life, transferring information into space through experiential immersions that challenge social, industrial, cultural, and academic perspectives.

IACT is designed to deliver four outcomes in students, including:

Growth in Critical Perspective - Through the introduction of creative theory and arts-catalyzed immersive experiences, students' ideas of what is and what can be in the world they live in will broaden in artistic, analytical and innovative ways. Critical perspective grows from empathetic appreciation of difference within teams, through engagement in the local urban and/or rural community, and through numerous exercises that challenge students to push beyond preconceived notions. Throughout IACT processes, students are challenged by each other, and to a lesser extent mentors, to think differently. This requires students to learn to be critics of others, as well as be open to critique. The habit of listening to others with understanding and empathy is integral to the development of this outcome. Further, IACT isn't about one major or discipline, nor one gender, race, or socioeconomic status. Transdisciplinary teamwork with interdependency emerges from valuing difference.

Growth in Creative Confidence - Growth in critical perspective helps to open students to other alternatives for solutions they are developing. But, confidence comes only after much practice. The IACT process exploits rapid prototyping, improvisational, and narrative storytelling activities, whereby students are challenged to innovate relative to technical or social challenges they are engaged in in order to help them create progressively quickly. Through exercises linked to these challenges, stu- 
dents develop the creative confidence to see the broad and diverse set of solutions in front of them and thus make leaps, trust their intuition, and chase solutions that they haven't totally figured out yet. A "fail fast" experience is integral to this creativity building process.

Successful Innovative Application - This outcome aims at developing students who can apply their improved critical perspective and creative confidence to any problem they are engaged in. Innovative Application in IACT is associated with the fearless practice of seeing the world in complex ways and experimenting with improbable materials in seeking imaginative, unexpected and innovative solutions. This process of applied creativity is 'humanity-centered', leading to designs that both connect emotionally to people and enable human flourishing. Critical here are meaningful interactions with as many stakeholders as possible. These include anyone who could be affected by their emerging concepts. The role of disruption is also critical, where students' emerging concepts are challenged through both individual and team-based exercises.

The deliverable for the innovative application is a holistic communication of the resulting solution, whereby students convey an intellectual and emotional understanding of their innovations, and in so doing, excite the audience about the potential impact of the concept students have developed. The installations often include sculpture, performance, video, sound, and creative writing and always seek to immerse viewers in the experience.

Expanded Vocational Perspective - IACT seeks to mature students' visions of their place in the world. It seeks to help students see more clearly who they are and how they fit into the world and with others. Plus, the humanity-centered emphasis on creativity helps students understand how they impact the world and generally inspires their interest in continuing to work on innovations which, above all, help people, after leaving the university.

\subsection{School of Engineering Visioneering Center}

The UD School of Engineering (SOE) Visioneering Center, established in January 2015 to particularly emphasize experiential learning that kindles curiosity, spark entrepreneurship to foster innovation, and develop collaborative skills among students, has embraced the IACT processes. Through the Visioneering Center, an IACT undergraduate certificate in Applied Creativity and Innovative Perspectives, sponsored by the School of Engineering, was established in 2016.

\section{Goals}

In this context, this project sought to explore the possibility of utilizing artscatalyzed processes and practices in humanity-centered engineering innovation challenges in two pilot programs in the summers of 2015 and 2016. The IACT learning outcomes of growth in critical perspective and creative confidence, successful innovative application, and improved vocational knowledge were to be measured. A trans- 
disciplinary collaborative environment was created, engaging engineering students collaboratively with students from business, sciences, humanities, and the arts. In these experiences, students were hired as interns, working full-time for 10-11 weeks.

The following sections describe the design of this pilot educational experience, the rationale for this design, the implementation details, results associated with student learning and the innovation challenge solutions themselves, and how the tested experience has and might inform the engineering curriculum.

\section{$4 \quad$ Project Details}

\subsection{Overview of Summer 2015 and 2016 Pilots}

In the summer of 2015 and 2016, with substantive support from the University of Dayton's Office of the Provost, two pilots were established as a partnerships between the Institute ofApplied Creativity for Transformation, the School of Engineering, and several project sponsors and community collaborators. The ideas behind this partnership emerged after planning discussions throughout the academic years previous to the summer experiences. Ultimately, the hope of these pilots, if successful, was to inform future curriculum.

The pilots were built around ten to eleven week internships for a multidisciplinary group of ideally upper class students. In the first year, four students were selected from Engineering, four from Business, one from Biology, two from Communications, and one from the Arts. In the second year, the intern make-up consisted of six engineering students, with the remainder coming from the Arts, Humanities, and Business. The full-time nature of the internship was identified as desirable for the opportunity to test a myriad of innovation and applied creativity processes.

In the first year, it was difficult to fill the internships due to a very late authorization to begin hiring for the summer. Thus, the marketing of the program in the first year was sparse. There were only 14 applicants for the 12 positions. In the second year, there were 30 applications, including 16 engineering students. In both years, one-third of the interns were from diverse backgrounds. In the first year, the application process was very traditional. Applicants were hired based upon their resume submission and a formal interview. In the second year, student applications required a creative submission which represented their perception of who they were and what they would contribute to this innovative, transdisciplinary experience. The subsequent interview consisted of a group interview, with three students being interviewed at a time. Each group was given 10 minutes to develop a creative demonstration that connected their individual creative submissions. During this interview, students could use anything available within the IACT Creator Space, a highly adaptable space conducive to rapid prototyping of concepts, or nothing at all. Some groups developed sculptures; others developed skits; others developed a story narrative. Ultimately, applicant selection was based upon the organizers' perspectives of individual student creativity, as well as their ability to create collectively with peers. Most striking was how ill- 
prepared nearly all of the engineering students were in contributing to the group contribution. Only four out of sixteen engineering students interviewed were active or highly active participants in their group interview process. There was a clear inability to create quickly and responsively to their peers. In the end, all students who were offered internships accepted.

The pilots engaged students in innovation challenges for sponsors seeking innovative solutions to problems with real human needs (called innovation challenges). Sponsors were asked to provide open-ended projects to permit testing of the artscatalyzed innovation approach for developing truly creative and unique solutions. Table 1 shows the innovation challenges and sponsors for the two pilot years. In the first year, the innovation challenges involved development of a product that would exploit recent sensor developments at the Air Force Research Labs (AFRL) and a plan to revitalize community in the City of Dayton. In the second year, the challenges were again a mix of technical and social. AFRL was seeking to change public perception of unmanned aircraft systems by developing a socially impactful demonstration utilizing drones. Another sponsor, the University of Dayton Research Institute (UDRI) was interested in developing a product leading to a potential start-up company centered on the use of additive manufacturing to impact energy use or sustainability throughout the world. Finally, Emerson Climate Technologies, a market leading manufacturer of refrigeration systems, was seeking a vision for human connectivity in 2050 that might help to inform future development of systems more integrally connected to people.

Table 1. Summary of sponsors/innovation challenges in 2015 and 2016 pilots

\begin{tabular}{|c|c|c|}
\hline Year & Sponsor & Innovation Project \\
\hline \multirow{2}{*}{2015} & $\begin{array}{l}\text { Air Force Research Labs } \\
(\text { AFRL })\end{array}$ & $\begin{array}{l}\text { Develop product utilizing sensors (any type) developed } \\
\text { by AFRL researchers }\end{array}$ \\
\hline & Collaboratory & Develop a long-term plan to revitalize the City of Dayton \\
\hline \multirow{3}{*}{2016} & Air Force Research Labs & $\begin{array}{l}\text { Develop a product that changes the way unmanned air } \\
\text { systems (drones) are perceived by the public }\end{array}$ \\
\hline & $\begin{array}{l}\text { University of Dayton Research } \\
\text { Institute (UDRI) }\end{array}$ & $\begin{array}{l}\text { Develop a product utilizing additive manufacturing that } \\
\text { impacts energy and/or sustainability throughout the world }\end{array}$ \\
\hline & Emerson Climate Technologies & $\begin{array}{l}\text { Develop an idea of what connectivity might mean in } 2050 \\
\text { to inform Internet of Everything possibilities }\end{array}$ \\
\hline
\end{tabular}

\subsection{Overview of Student Mentoring}

Fig. 1 shows the process and mentoring progression in the pilots. While the roles are shown progressing serially in each channel, there was necessarily strong interplay between each process track. IACT educators were primarily responsible for designing and managing the process. In all stages, from orientation, to the Bootcamp used to jump start development of critical perspective and creative confidence, and to innovative application, arts processes and habits were used to assist collaboration, grow critical thinking, and assist the ideation process.

The School of Engineering faculty provided assistance in the ideation process, complementing the arts-based approaches with more conventional ideation pathways. 

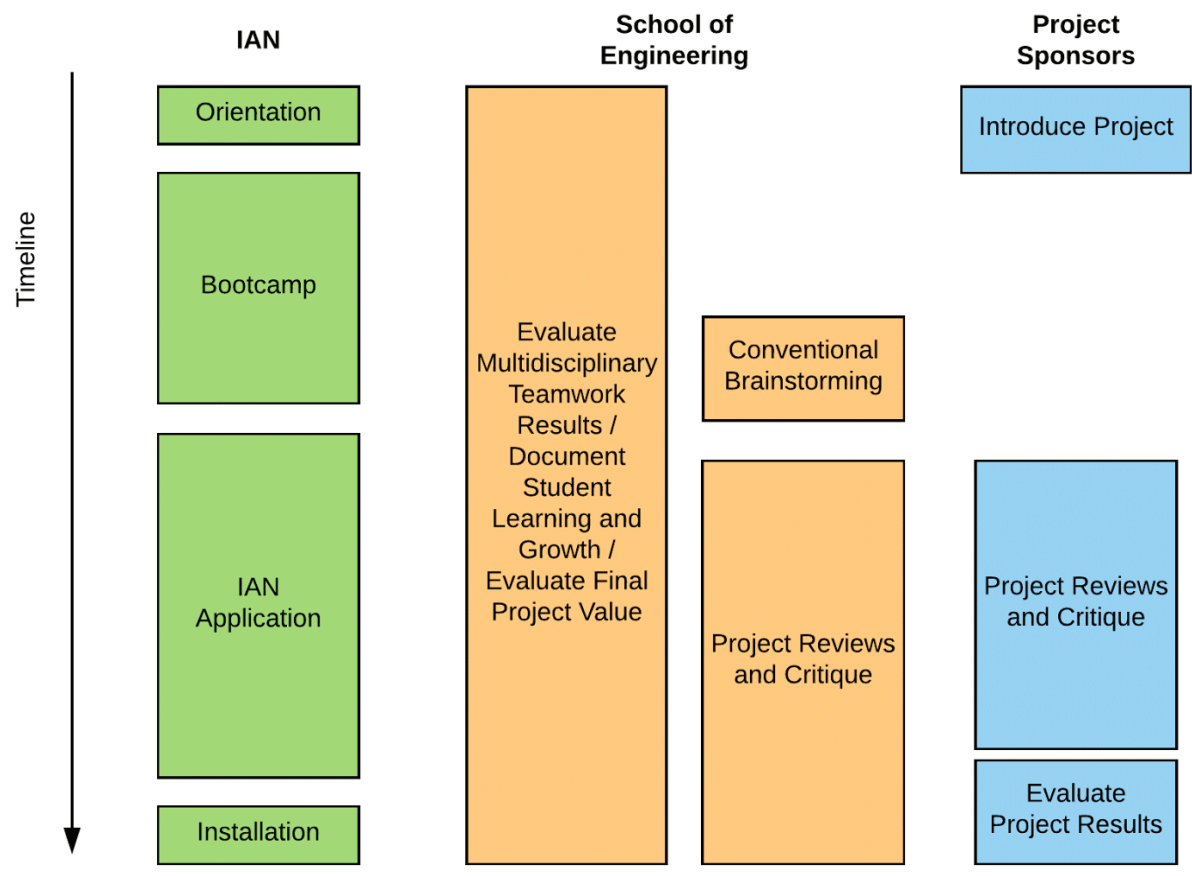

Fig. 1. Longitudinal progression of summer process and mentorship roles of collaborating constituencies

They also were responsible for helping to critique weekly team project updates and progress and for evaluating student growth in terms of multidisciplinary teamwork and creativity, as well as evaluating the final project results. Project sponsors were responsible for orienting students to their challenges, attending/critiquing the weekly project updates, answering any questions students had along the way, and evaluating the final project results.

The following section details the arts processes and practices employed to render the outcomes of critical perspective, creative confidence, innovation application, innovative installation, and vocational knowledge.

\subsection{Description of Arts Processes and Practices}

Nine fundamental principles guide the IACT arts catalyzed practices and processes. These are detailed as follows. Where appropriate, examples are provided to better illustrate the process.

1. The IACT processes are contextual. This is the most important IACT principle. All exercises and activities are connected in some way to the innovation challenges the students are engaged in. There are two reasons for this. First, students truly want to succeed in their projects, and because they trust the process and the people involved in leading it, as well as each other, they value that the development activities 
connect in some way to the challenge(s) they are involved with. Secondly, the end goal is for the sponsor to perceive the innovation challenge solutions as truly spectacular.

Consider the 'humanity-centered' aspect of the innovation challenges of pilot offerings. In the first year of the Collaborator Accelerator, students were challenged to explore the Dayton community to better understand needs and wants in the urban environment in order to develop a revitalization plan for the City of Dayton. Much of this experience was arranged by one of the project sponsors. In the second summer, students designed their community experiences to: help them better understand human needs in communities relative to their project(s); to elicit ideas from the community for their project; and to have a sounding board for their emerging ideas. For example, interns participated in an arts event downtown (Art in the City) early in their project process. The project teams created an interactive, visual experience in order to gather information related to their project, as shown visually in Fig. 2. Through this experience, they surveyed attendees in an effort to discern what people in the community might think about their problem. For example, the unmanned air systems team asked community members about their perceptions of drones. The additive manufacturing team explored perceptions of energy, discovering that many community members equated energy with time, rather than simply in relation to natural or physical resources.

As the challenge solutions evolved, there was more outreach into the community with a focus on stakeholders who could help inform their ideas. For example, the unmanned air systems team, after identifying a 'lifesaver drone' concept, reached out to police and medical emergency care professionals in the Dayton area to see if they could help to inform their ideas for a first responder medical drone. The input coming from these constituents was invaluable in helping mature ideas for the students' final solution. The additive manufacturing team visited local urban farmers working to erase the urban food desert, as well as a vertical farming manufacturer operating in Ohio. Interestingly, while many engineering design projects ask students to design for various stakeholders, there isn't generally a strong and direct linkage to community, both in discerning needs and growing ideas. The opportunity to humanize the problem is generally lost.

Last of all, the IACT Innovative Installation ultimately involves the stakeholders who potentially could benefit from the concept, to best gauge the value of the students' ideas and the effectiveness of students' intellectual/emotional expression of their final solution.

2. IACT activities are intended to be multi-layered. The process of ideation, disruption, and "A-Ha!" make up the core design of IACT exercises. The intent is to help students see that their individual and even small team ideation or critical perception analysis is limited by who they are. The ideation phase focuses on the collection of information (the content), the ambiguity of the unknown, and the tension, or obstacle that emerges as a result. Disruption activities are intended to shock students out of their comfort zone - to help them see a wider framework through empathy and collaboration. Disruption leads to "A-Ha!" enlightenment — the unexpected outcome and new knowledge from which improved perspective or innovation can emerge. 


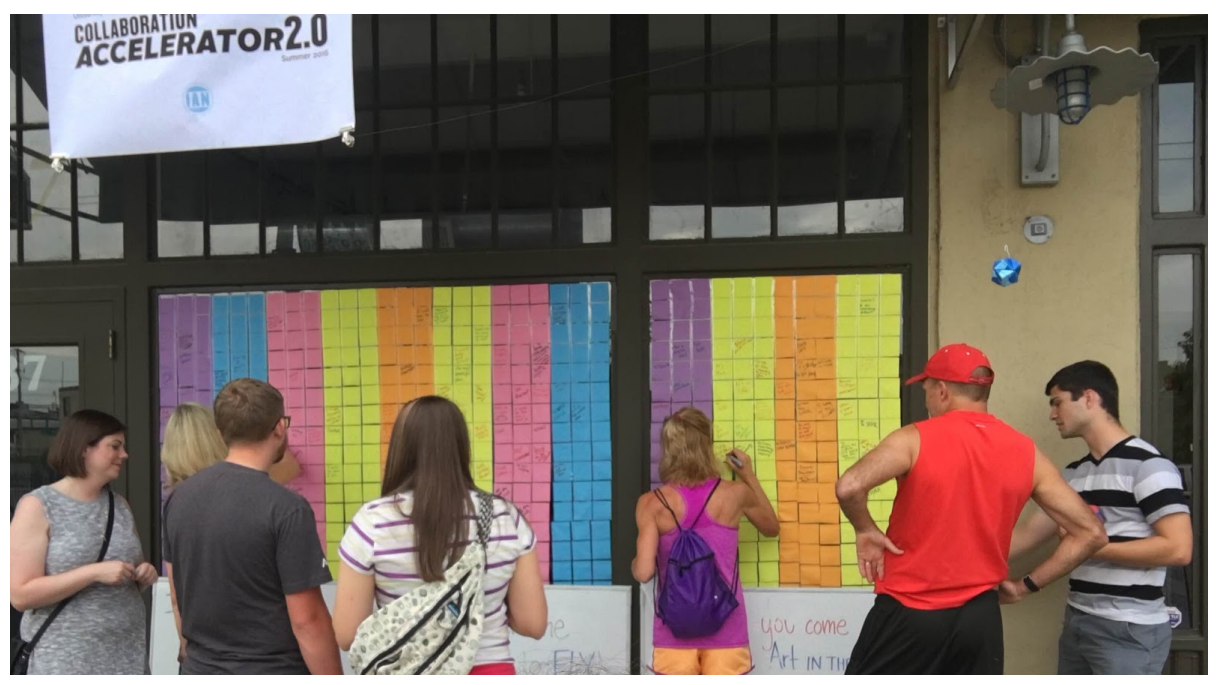

Fig. 2. Arts in the City interactive experience to gather information from community members

As an example, consider the Bootcamp exercise entitled "Ideation - Seeing in Complex Ways". This activity was developed in order to help students see the constraints that a limited point of view places on their ideation. In this activity, students viewed incomplete quotes from scholars or public figures that could be taken out of context without prior knowledge or background info. They were tasked with responding to each quote during a three round written process. In the first round, they had 30 seconds and "limited characters" to respond. The individual student responses were then passed to a peer student, who was tasked to write a response with no more characters and within an even shorter time period. The responses were then passed to a third student, who then responded with one word. In the next phase, individual students viewed each entire quote (and its source) and again proceeded through multiple rounds of response. However, in the second round, they were permitted 140 characters and four times the original time to respond to the information shared. After several rounds, students understood that the transmitted information was much improved; ideally they learned the value of informed listening. In the last layer, the student responses were then posted on the wall and discussed, art critique style. Students' responses were kept "anonymous" unless a student chose to self-identify something they wrote. Ideally they leave this exercise with a more cautious attitude toward acceptance of information provided to them, and an understanding of how their thoughts and reactions can be constrained by their own perceptions and biases.

3. Critical perspective and creative confidence development, require practice - and lots of it. Students are tasked with critiquing and creating with increasing pace in order to help to make such skills second nature for them. In fact, the one aspect of the Bootcamp experience that is most shocking to the students is the pace expected of them in responding to multitudes of challenges. This pace element of the IACT process contrasts greatly with the expectations of students in their normal courses. Argu- 
ably for engineering students the most challenging experiences they face in terms of pace are examinations.

Consider one of the first days in the Bootcamp. An early activity aimed to help students see how their own biases might restrict their solutions. They were tasked with imagining where solutions to their innovation challenges might be in 2050, utilizing a "Future Back" process [22]. Students were asked to respond to three questions: "What are the possibilities?" "How can we do things differently?" "Where do we go next?"

After ideating, students were then given a bag of improbable materials to evoke greater thinking. The materials provided had different functions, textures, sound, colors, as well as visual and emotional connotations, all serving as prods for ideation. Within a mere 15 minute time period, students were tasked to create a rapid prototype (a truly non-artistic sculptural representation of their work) that represented a view of their solution from a 2050 perspective, using only the materials in their bags. As a follow-up to this exercise, students were then asked to think about their notion of the future as it is shaped by today's constraints. To help them develop deeper understanding, students viewed two videos — a 1962 Jetsons cartoon visioning 2062 living, and an excerpt from the 1989 movie Back to Future showing a perception of the 2015 world. The former relied upon conveyor belts for production, emphasized a traditional nuclear family, automation, pneumatic tubes for transportation, and living above the "smog" zone. The latter showed holograms and flying cars. Student teams were then asked to think more deeply about how the constraints placed upon them from their place in the current world affected their perception of 2050 possibilities.

The afternoon activities then focused on a 4D immersion (sight, sound, space and emotion) aimed at helping them understand more, or see for the first time, how they are impacted by the visual culture they are surrounded by. They first experienced three rapid fire presentations that included the concept of "cultural artifact" discussed through the Stanford 2025 educational plan developed by Stanford design students [23]; examples of site-specific installation art; and examples of visual storytelling. The total time for these three presentations done by three different people was thirty minutes.

The whole group was then given 45 minutes to stretch/break their collective notion of visual culture by creating a room (within the IACT Creator Space - See Fig. 3) that represented Dayton 2016 as an artifact viewed from 2050 (We've been to the future, now what does 2016 look like as an artifact of the past?). Students were instructed that their immersion should represent the voice of the entire group, while utilizing the created "visual culture" from the improbable materials as the catalyst.

At the conclusion of this activity, students were individually and collectively tasked with critically observing the 4D design the group came up with, and listing all of the unexpected outcomes observed from the final design. Then they were asked to channel these observations to consider additional possibilities and challenges emerging from their identified unexpected outcomes.

This clearly was a very busy day.

4. IACT processes emphasize development of empathy for others (teammates and people affected by design). In many cases within an IACT challenge or experi- 
ence, a disruption is presented as an obstacle or hurdle that stems from the introduction of content with multiple layers. Tension arises within the ambiguity of the presented content. Often when faced with this tension, students will rush to a solution in avoidance of the potential obstacle that the perceived ambiguity places on them, or they will freeze in the face of the obstacle. Upon the understanding or reveal of the specific disruption within a particular challenge, the IACT process looks toward empathy as the vital next step in authenticating the cause or purpose behind all disruptions. Learned empathy becomes an honest collaborative process that both lessens the pressure of a single student's response to the disruption while also allowing multiple student experiences (academic, social, etc) to inform a potential new A-Ha! As a result of students collaborating with and respecting the ideas and experiences of their peers, the framework widens to present more possible solutions, as well as improve the richness of these potential solutions.

For instance, if a group of students are presented with a challenge question that lends itself to numerous solutions, this instantaneously becomes a disruption to the first, assumed solution envisioned. Students are then asked to 'drill-down' using various 'speed-dating' techniques. In one example, students answer a series of value based, personal interview questions related to their challenges that they also share with each other. They then bundle the responses into themes, looking to reframe the original challenge with a deeper, more personal truth, thus providing the students a new, empathetic view of potential solutions just by being introduced to each other's personal and professional values. The success of the resulting solution must be based upon an understanding of the the positive and negative of potential results as it affects the human user (ie. innovative empathy).

5. IACT innovation activities and deliverables are 4D. IACT innovation relies upon 4D (light, space, sound and emotion) immersive experiences to transfer information. This arts-catalyzed concept is the heartbeat and soul of the IACT creative and innovative process. When presented with a challenge and asked for a marketable idea or solution, the students are confronted with the understanding that the deliverable result will not be simply a Powerpoint presentation or a white paper, something very common in industry. Rather, it must be something for observers to fully interact with - intellectually and emotionally. The 4D design space, shown being actively used in Fig. 3, rethinks traditional models of art galleries and theatre spaces by merging them into an unconventional space where the narrative journey of creative application is brought to life. The building of a 'world' in which the innovative solutions exist enables stakeholders and other interested parties to explore through sight, space, sound and experience emotional reactions to the solutions. This aspect of IACT is a crucial step for both humanity-centered innovation and empathy development. IACT students must have the confidence to tell a story within their solution. This story defines the journey of their challenge. This journey's unexpected outcome is the emotional response to the solution and its impact on society.

6. Critical evaluation is built into everything. Arts students are accustomed to critique, and sometimes scathing critique. In the end, they understand that it makes them better. Engineering students, in contrast, aren't used to being told "Your proposed solution doesn't actually address the problem" or "You haven't listened to your 


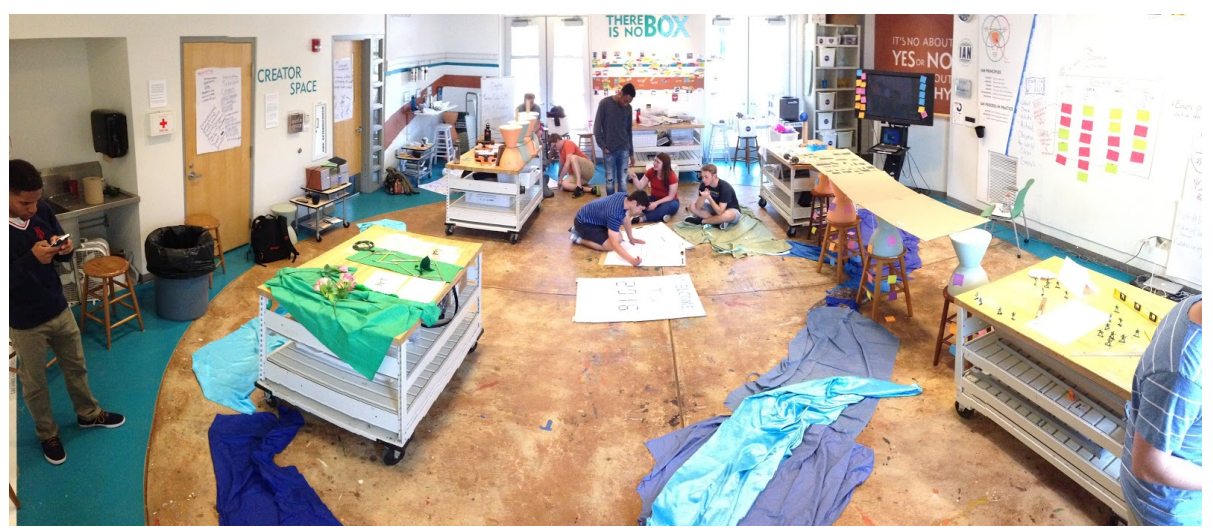

Fig. 3. 4D design space in use for rapid prototyping in the IACT Creator Space

peers"-- or -- "You haven't respected your peers' ideas or empathized with them," etc... They are used to being in processes that expect them to succeed - the first time. They aren't accustomed to being in a situation where they are permitted to fail. By contrast, habitual practice of critical evaluation throughout the IACT process helps embed the skills of critical thinking and critical perspective in the mindset of students. It's the wherewithal and ability to be exhaustive in the exploration and examination of ideas, concepts, and contextual underpinnings that are historical, contemporary and futuristic — sometimes all within the same moment. This process of approaching challenges is fostered by the unrelenting expectations of students to be comfortable with navigating ambiguity, assumptions, perceptions, and belief systems in the way information is presented and received - in search of a deeper revelation. Further, IACT educators share critique from a transdisciplinary perspective that allows for a vast array of diverse backgrounds, disciplines, experiences, and values. In the process, students not only own their individual identity, but also develop the skills to embody the complex identities of those around them and the world at large. As such, IACT students often times relish the chance to both give and receive critical feedback that yields a transformative mindset, thought pattern, and communal space for growth.

7. The IACT process requires self-learning. Many IACT exercises end with a "Hot-Wash", which is a time for students to briefly reflect on what they learned about a specific experience. They are challenged to think about how the biases they bring from their personal backgrounds and field of study have affected their ideas. They are challenged to think about how they might improve their interdependent teamwork. Finally, they are challenged to think about how what they are doing impacts their perspective of their personal vocation. The IACT experience is intended to transform students' understanding of who they are, how they fit in the world, and what they might do professionally in the world to help shape it.

In a "Hot-Wash", students are led through two very quick processes, no longer than fifteen minutes. Students begin with what is affectionately called "One-Mic," a nod to legendary Hip Hop artist Nasir (Nas) Jones' song of same title that continually asks, "What do I have to do to get somebody to turn around and hear what I'm saying and 
take it serious?". In this open, non-judgemental space, students are encouraged to release emotions and responses out loud in single words. This is meant to free their anger, frustration, happiness or any immediate feelings that could cloud part two of the "Hot-Wash". After a brief 2-3 minute 'One-Mic' experience, the students then are presented with two questions. The first question is typically focused on the "A-Ha!" outcome of the exercise they have just completed and what might be next. The second question is repetitive for each and every "Hot-Wash" and asks students how the experience they just went through applies to their specific discipline of study or even their mission as a student learner and creator. This consistent second question is both meant to reinforce the importance of the IACT process as a creative application to their major and personal experience, and to be a reminder for students to continually look to reframe their discipline through potential creative lenses as they develop stronger innovative skills of application.

8. All IACT processes are adaptive. IACT educators are continuously looking for deficiencies in the students' concepts and understanding, and developing corrective activities that help students discern such deficiencies on their own. This adaptability in the process is certainly an artistic habit. This process is not an exact science, nor is it an instantaneous or one-time discernment from either the IACT educators or students. As with any adaptive and additive design, the ability to first be aware of the tension that emerges from a deficiency made present is key. This correlates directly with the "fail fast, fail often" IDEO approach to human-centered innovation. In this process, students' rapid prototype solutions are immediately challenged by peers and educators [24]. It is here where a student learns, not from actual failure, but from deficiency of experience or perspective. The adaptive process looks to make light of blind spots in a student while encouraging and challenging them to continue to hone those areas and prepare for continued learning through the innovative challenge.

9. IACT skill development and innovative application emphasize transdisciplinary creativity, thinking, and practice. The desired outcome of the IACT process is built specifically around the concept of applied creativity. The word applied distinguishes itself from the theoretical and the pure to be one in consultation and partnership with other people and other purposes. Thus the students' creative skill development must emphasize collaboration with others, and must be fully engaged with the experiences and creative thinking and problem-solving of others. Each student's specific journey contains great experience, anecdote, and knowledge. When applied to another's journey, the narrative grows, merging thoughts and experiences for varied additive results. When students discover shared success over similar disruptions, be it same or different outcomes, then confidence in themselves and, more importantly, in each other, strengthens. That collaborative journey then, in turn, impacts the student's own personal and professional growth. 


\section{Results: Student Work}

\subsection{Overview of Student Innovations}

The projects selected were intentionally highly open-ended. There were no preconceived solutions. Thus, the originality of the solutions developed and their success in meeting human needs is perhaps the most important measurable from the experience. The following summarizes the solutions and the final presentations developed.

The unmanned air systems (UAS) team sought to change public perception of drones through the development of a new UAS technology or use. Their innovation was an Emergency Medical Service drone that would be first responder to medical emergencies, arriving to a site more quickly than an ambulance. In so doing, it would be able to surveil a site to affirm safety, do preliminary triage such as at a car accident site, communicate directly with patients or bystanders to help assess needs, and even provide emergency supplies that could be administered by bystanders (such as defibrillators or aspirin for potential stroke treatment).

The additive manufacturing team's innovation addressed energy from a food perspective, seeking a means to grow locally anywhere. They proposed additive manufactured vertical farming systems targeted for anything from individual grower to mass-produced factory farm scales. Their design aimed to deliver only the water (and nutrients) needed by the crops and support the weight of the crops as they matured. While energy was the driver for their design, reducing water required was especially considered important, as water shortages threaten much of the world. Their vertical farming system would be designed to use at least $70 \%$ less water.

The connectivity team simply looked to define what connectivity might be in 2050, and why people feel the need to be "connected." They offered a solution based upon the idea that true and meaningful connectivity required people to first overcome fear - fear that can either incite change or hinder progress and innovation. It is prefaced on the idea that people first have to really seek to understand others in order to connect authentically. They also envisioned how technology could both enable these overcoming fear obstacles and enable connectivity with fear boundaries overcome.

Given the human-centered emphasis of the designs, the final presentations were expected to convey both the essence of their designs (What?) and how their designs met human needs. Thus, the presentations were expected to invoke an emotional response. The unmanned air systems team developed a theater-like experience. The viewers witnessed an accident with an injured person lying unconscious outside of the vehicle. A bystander called 911. Both an EMS drone and ambulance were dispatched. Viewers saw video of the ambulance moving toward the site, while experiencing the drone's arrival well before-hand. They observed the interactions between the drone controller and the bystander. In these, the bystander was asked to observe if the injured person had a pulse. He didn't. Then, the bystander was guided by the drone controller through the process of accessing and then using the on-board defibrillator. The injured person's pulse was restored. The sketch ended with the ambulance squad arriving to transport the injured person to a hospital. See Fig. 4 for an image of the participatory installation for this challenge. 


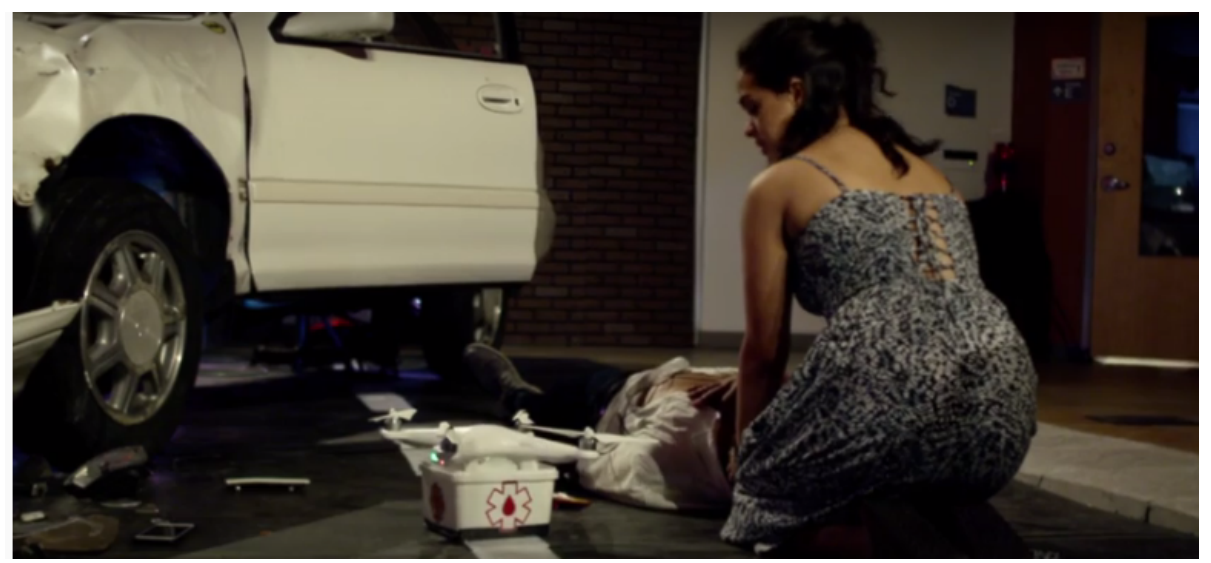

Fig. 4. Final immersive installation for UAS challenge

The installation for the vertical farming through additive manufacturing project walked the observer through three spaces. In the first, observers could experience the reality of urban food deserts, participating in a typical meal available to poor urban residents. In the next space, they were provided a visual depiction of traditional mass agriculture; with much water and nutrient use (with run-off). They were also immersed in a world threatened by water shortages. In the final space, they were able to see and use prototypes of the vertical farming solutions, as well as access a website that would permit them to select a design tailored to their gardening interests.

Last of all, the final installation for the connectivity team immersed viewers through a historical experience of connectivity, moving from the superficial to fear to the origins of connectivity. It then moved viewers through their own 'A-Ha' experience, one that helped them see how people can truly connect with others -- especially showing the importance of individual being challenged to step outside of themselves in order to truly connect with others. The immersive experience finally concluded with a 2050 perspective of connectivity that helps human flourish.

\subsection{Mentor and Student Assessment of Student Innovations}

So, were the results successful? The findings that follow from surveys of students and mentors, as well as analysis of student reflections about their experience, focus on the second pilot, as this pilot represented a more evolved application of the IACT process to the innovation challenges. The results that follow, while certainly not statistically relevant, do in fact support an action research methodology, e.g., a disciplined process of inquiry conducted by and for those taking the action in an effort to improve the piloted pedagogy [25].

Relative to the quality of the produced student work, the survey results show that both students and project sponsors believed that the innovation challenges had been successful. Table 2 summarizes student and project sponsor/mentor assessment of student success in developing a truly innovative solution, the effectiveness of the 
solution in addressing and meeting real human needs, and the effectiveness of the final installation in both informing and emotionally capturing observers. A scale of 15 is used, with 5 representing the most positive response. It is clear from Table 2 that students, mentors and sponsors felt students had successfully or highly successfully developed innovative solutions that connected to real human needs. They also felt that the final installations succeeded in describing the innovations, while also providing an emotional connection to observers. Somewhat interesting is that students' perception of the innovativeness of the unmanned air systems project was slightly lower than the other innovation challenges; while challenge sponsors/educators perceived it to be the most innovative solution by far.

Student growth relative to the noted learning outcomes was also assessed via survey. The survey instrument employed was used to evaluate growth relative to: creative confidence; critical perspective; empathy for others; transdisciplinary teamwork; human-centered design capability; and communications (both informative and emotional). Table 3 summarizes results from the survey, which was administered at the conclusion of the summer program. Student self-assessment and project mentor assessment relative to growth in these categories is shown. The mentor evaluation is further organized by project.

\subsection{Mentor and Student Assessment of Learning and Growth}

In general, student assessment of their own growth mirrors mentor assessment. The only category with significant difference was relative to growth in effective communications, where educators observed greater improvement than students observed in themselves. It is also clear from Table 3 that project educators recognized less positively the growth of students involved in the Additive Manufacturing project. Interestingly, this team was comprised of three engineers and one business student. Two of the individuals involved in the team were very hesitant to move away from ideas they embraced individually, even when their ideas weren't viable for the challenge presented.

The learning impact can't just be measured from just a survey. Post-experience reflections by the students offer more detail. Asked to comment on their takeaways from the summer, a Civil Engineering student wrote "I'm not sure just yet of all of the takeaways from this summer. I learned more than I can put in a few words." This sentiment was expressed by many of the students. They struggled to describe all of the ways that the experience had helped them grow and change.

A number of the students' response to the takeaways question was that they had gained a newfound creative confidence. As an English major (formerly a Chemical Engineering major) described, "I have not always been part of a 'creative' field, but I have always been a creator. I was always afraid to show my work. I was afraid of criticism. I was afraid of expectations. I was afraid that I would produce garbage. I was afraid that I would produce something that I could not follow up. After this program, I know that I can create something amazing." An engineering student responded similarly. He wrote "The Collaboration Accelerator gave me the tools I needed to create innovative solutions that truly address human centered design. Before coming 
Table 2. Student and Project Sponsor/Mentor Evaluation of Project Success (1-Not Innovative at All, 3-Slightly Innovative, 5 - Very Innovative)

\begin{tabular}{|l|l|l|l|l|l|l|}
\hline \multirow{2}{*}{ Evaluation Topic } & \multicolumn{3}{c|}{ Student } & \multicolumn{3}{c|}{$\begin{array}{c}\text { Project Sponsor/ } \\
\text { Mentor }\end{array}$} \\
\cline { 2 - 8 } & UAS & AM & Con & UAS & AM & Con \\
\hline Innovativeness of the Solution Developed & 4.3 & 4.5 & 4.5 & 4.88 & 3.88 & 4.75 \\
\hline $\begin{array}{l}\text { Effectiveness of Solution in Meeting Real Human } \\
\text { Needs }\end{array}$ & 4.7 & 4.3 & 4.1 & 5.0 & 4.29 & 4.88 \\
\hline $\begin{array}{l}\text { Effectiveness of Final Presentation in Describing } \\
\text { and Connecting Emotionally }\end{array}$ & 4.75 & 4.13 & 4.63 & 5.0 & 4.38 & 4.88 \\
\hline
\end{tabular}

Table 3. Student and Project Sponsor/Mentor Evaluation of Student Growth (1-None, 3-Some, 5 - Very Significant)

\begin{tabular}{|c|c|c|c|c|}
\hline \multirow{2}{*}{ Student Growth in... } & \multirow{2}{*}{$\begin{array}{c}\text { Student Self } \\
\text { Assessment }\end{array}$} & \multicolumn{3}{|c|}{ Project Mentor Assessment } \\
\hline & & $U A S$ & $A M$ & Con \\
\hline Creative Confidence & 4.4 & 4.8 & 3.4 & 4.4 \\
\hline Critical Perspective & 4.5 & 4.8 & 3.6 & 4.8 \\
\hline Empathy toward Others & 4.5 & 4.8 & 3.2 & 4.8 \\
\hline Multidisciplinary Teamwork & 4.4 & 5.0 & 3.4 & 4.8 \\
\hline Human-Centered Design Capability & 4.4 & \multicolumn{3}{|c|}{ Not evaluated } \\
\hline Communications (Informative and Emotional) & 3.8 & 4.8 & 4.4 & 4.8 \\
\hline
\end{tabular}

into this program, I would have been engineering products with only one core characteristic in mind - function. Now when I look at a design problem, I know how to gauge innate reactions, identify past and future references, and analyze societal tastes to design inventions on a whole separate level. I've caught the creative bug of forever looking at everyday life and asking myself 'how can I innovate this?' "A Communications major self-identified as a visual artist offered, "Understanding the concepts and truth behind IACT showcased a new (perspective) of creativity, a facet I, as an artist, had yet to explore. I loved every minute of the tension and process of understanding something I had never learned before." Finally, an engineering student related that her biggest takeaway was a "broader application of creativity and "creative confidence' that will help me play a more unique role in any job or project I am involved in." She noted that this growth was especially important to her, given her that from her perspective, "creativity is noticeably absent in much of the existing (engineering) curriculum." 
Relative to empathy for others and teamwork, one engineering student noted how the experience especially opened him up to ideas and ways of thinking from people who were different from him. This perspective was also shared by a Humanities student, who acknowledged that the experience helped her appreciate the knowledge and skills expressed from disciplines other than her own. A communications student who acknowledged that he had always been the 'captain', wrote "I grew to appreciate and trust in everyone's unique talents and abilities....As I leave the Collaboration Accelerator, one of the biggest ways I will summarize this 'A-ha' moment is 'people first."' An International Studies major offered "I would say that my takeaways start with team building. I grew so much in this process in the sense that I am not the center of progress but rather a team is. I feel humbled and ecstatic about the fact that I learned new methods of thinking and approaching others." Finally, an engineering student wrote "I have gained new perspectives through working with people of different mindsets and skillsets this summer. I feel like I have a broader view of design that will lead me to consider more of the human implications to my design work."

Lastly, relative to communications, one of the engineering students noted how important he now sees communications; especially in communicating in language that all can understand. His perspective on communications was echoed by another engineering student, who wrote "Every word I said, every description I gave, and every phrase we coined as a team had an impact on the way people thought and acted."

Perhaps the most exciting result from the experience is the impact that the experience had on students' notion of their vocation; e.g., what they wanted to do beyond their degree. Sixty percent of the students said that the experience had impacted their vision of their future vocation very significantly. Twenty percent claimed a significant impact. The remaining twenty percent claimed some impact. Many of their personal reflections strongly elicit how the experience changed their vision of their future. The lone business student related "Moving forward to the beginning of my career, I will be doing my best to seek out companies/positions where cross-disciplinary collaboration, innovation, forward thinking are of the utmost importance... I realized through this program that I enjoy creating the visual experiences that communicate the solutions to problems... I will be seeking positions where I can explore this newly found passion." A female engineering student related that, as a result of her experience in the summer pilot, she will now be looking to be involved in a "think tank" type setting. An arts major related that he sees his future vocation as one that will have him work "with people different than my own major and continue to innovate." One of the engineers who had noted growth in creative confidence and curiosity, now wants to work in an environment where these skills can be appreciated. Another engineer said "My real goal is to use and mix the technical skills from engineering and my interpersonal skills in creativity and innovation, and apply them wherever I end up - whether it is in academia, nonprofits, or a small start-up. So this internship is not something I will just apply to my career, it is the beginning of it." Finally, the English major wrote "I think that this program has verified what I already knew. I knew that there was more to being an English major than being a writer or teacher, and this internship showed me that I have skills that are deeper and more impactful than that." 


\section{Curricular Ramifications of Findings}

While this pilot was not part of the curriculum, the learning impact on students was clear. Growth in creativity and creative confidence, critical perspective, ability to work in teams across disciplines, ability to communicate more holistically, and ability to design systems needed by people (humanity-centered design) were all observed. Inarguably these skills are important. The question here is "How might these be addressed in the engineering curriculum?"

Design courses certainly offer opportunities to address many of these qualities. The IACT processes offer significant value in particularly the ideation phases of design projects, by asking students to create quickly and from different perspectives. In a sense, the IACT process seeks to broaden the ideas emerging as it asks students to view their problems from perspectives separate from their own experiences and their discipline. The IACT process also brings a tension element to acceptance of the best of the early ideas. It also helps to enable the ideal of "Fail fast and fail early." Too many design courses from our experience ask students to come up with a few ideas, pick the best based upon some rational metric, and move the best forward. While failing fast and failing early may be the ideal, students in general don't have to develop enough ideas quickly enough and from as many perspectives as possible in order to be in position to fail. Additionally, the IACT processes seek to evoke an emotional connection for students as they envision solutions that meet real human needs. Clearly, engineering design courses haven't sought to make these connections.

But engaging only engineers in design efforts is a big shortcoming of the vast majority of engineering design courses. Not broadening participation in engineering design projects to include students from the arts, business, social sciences, sciences, and education is a lost opportunity. Exposing engineering students to different ways of thinking is essential for growth in creativity. If engineering students can see the value of ideas from peers other than engineers, they will be less likely to be constrained by the boundaries of their own discipline. Moreover, in the process they will necessarily have to be able to communicate their ideas and processes understandably to people who aren't them. Further, the IACT process, which asks students to create from different perspectives, is a tremendous asset for insuring that the cultural wealth coming from the unique experiences of each student, associated with their own gender, race, and socioeconomic status, help to inform the solutions that are developed.

Finally, design courses offer an opportunity to communicate engineering solutions through more than reports and Powerpoint presentations. The IACT process enables students to communicate their solutions not just in terms of information but also in terms of the real human impact their solutions have.

While design courses offer a potential home for IACT processes, it is essential to understand that if developing innovative engineers is a goal of engineering education, then creativity shouldn't be relegated to some first year engineering design course and a capstone course. It should be in everything. Engineering courses which ask students to simply apply theory covered to a rote problem that all students do is a wasted opportunity, both for learning better how to apply the theory and for nurturing growth in creativity and innovativeness. For example, instead of asking an engineer to analyze a 
heat transfer problem, such as determining the heat transfer through a wall for known boundary conditions, couldn't students be challenged to develop a new technology that requires use of heat transfer fundamentals to a new innovation -- to something like wearable clothing technology that provides controlled human thermal comfort?

All creative efforts should also come with scrutiny, especially scrutiny coming from their peers or anyone (alumni?). Students should learn how to be strong with a critique of others and they should learn how to accept critique from others. This latter skill was something that was observed to be very lacking in the engineers participating in the summer internships over the past two summers. They did not like their ideas challenged. In some cases, they were unwilling to budge from their ideas even as evidence was brought to light that demonstrated significant weakness in their ideas. Every engineering course offers opportunities for students to both critique peers and be critiqued by peers.

Finally, there could and should be a significant rethinking of what is meant by a course. For the most part, engineering programs have chunked courses into 3 or 4 credits, with engineering students taking anywhere from four to six courses per semester. Couldn't engineering students be engaged in an on-campus internship such as the one described in this paper? This internship might comprise all or at least half of the credits students enrolled in for a semester. The life-impactful learning realized from this experiment could be available for all students.

\section{$7 \quad$ References}

[1] R. Florida, The Rise of the Creative Class, New York, New York: Basic Books, 2001.

[2] K. Foundation., "The Importance of Young Firms for Economic Growth," Entrepreneurship Policy Digest, 14 Sept. 2015.

[3] R. J. Sternberg, The Nature of Creativity: Contemporary Psychological Perspectives s., Cambridge, England: Cambridge University Pres, 1998.

[4] J. R. Plucker, R. Beghetto and G. Dow, "Why Isn’t Creativity More Important to Educational Psychologists? Potentials, Pitfalls, and Future," Educ. Psychol., vol. 392, pp. 83-96, 2004. https://doi.org/10.1207/s15326985ep3902 1

[5] K. Kazerounian and S. Foley, "Barriers to creativity in engineering education: A study of instructors and students perceptions," Journal of Mechanical Design , vol. 129, pp. 761768, 2007. https://doi.org/10.1115/1.2739569

[6] S. Jaschik, "Well Prepared in Their Eyes," Inside Higher Education, 21 Jan. 2015.

[7] B. Zare, "Creativity Differences between Art and Engineering Students," in Proceedings of the International Conference on E-business, Management and Economics, Singapore, Indonesia, 2011.

[8] C. Charyton and G. E. Snelbecker, "General, Artistic and Scientific Creativity Attributes of Engineering and Music Students," Creativity Research Journal, vol. 19, no. 2-3, pp. 213225, 2007. https://doi.org/10.1080/10400410701397271

[9] G. Ragusa, "Engineering creativity and propensity for innovative thinking in undergraduate and graduate students," in ASEE Annual Conference \& Exposition, Vancouver, BC., 2011.

[10] National Academy of Engineering, The Engineer of 2020: Visions of Engineering in the New Century, Washington D.C.: National Academies Press, 2004.

[11] J. Hall and M. E. Johnson, "When Should a Process Be Art, Not Science?," Harvard Business Review, March 2009.

[12] A. Styhre and M. Eriksson, "Bring in the Arts and Get the Creativity for Free: A Study of the Artists in Residence Project, Creativity and Innovation Managemen," Creativity and 
Innovation Management, vol. 17, no. 1, p. 47, 2007. https://doi.org/10.1111/j.14678691.2007.00458.x

[13] A. Furnham, M. Batey, T. W. Booth, V. Patel and D. Lozinskaya, "Individual difference predictors of creativity in Art and Science students," Thinking Skills and Creativity, vol. 6, no. 2, pp. 114-121, 2011. https://doi.org/10.1016/j.tsc.2011.01.006

[14] M. Hardiman, L. Rinne and J. Yarmolinskaya, "The effects of arts integration on long-term retention of content," Mind, Brain, and Education, vol. 8, pp. 144-148, 2014. https://doi.org/10.1111/mbe.12053

[15] The Kennedy Center, "Selected Findings from The John F. Kennedy Center's Arts in Education Reasearch Study: An Impact Evaluation of Arts-Integrated Instruction Through the Changing Education Through the Arts (CETA) Program," The Kennedy Center, Washington D.C., 2014.

[16] J. Katz-Buonincontro, "Fanning the fires of conflict or leading with empathy? Creative problem solving through improvisational role-playing," CanadIACT Review of Art Education: Research and Issues (CRAE), Invited article for a Special Edition on aesthetics and empathy, no. Sept., 2015 .

[17] J. Katz-Buonincontro, Phillips, J. and N. W. Arnold, "Developing school leaders through the arts: New directions in teaching and research," Journal of School Leadership, vol. 26, no. 6, pp. 1169-1202, 2015 .

[18] R. Russell and K. Hutzel, "Promoting Social and Emotional Learning through ServiceLearning Art Projects," Art Education, vol. 60, no. 3, pp. 6-11, 2007.

[19] N. Gnezda, "Cognition and emotions in the creative process," Art Education, vol. 64 , no. 1 , pp. 47-52, 2011.

[20] A. Costa and B. Kallick, Discovering and Exploring Habits of Mind, Association for Supervision \& Curriculum Development, 2000.

[21] MIT, "Arts at MIT," [Online]. Available: http://arts.mit.edu/welcome/cast/about/. [Accessed 1512016 ].

[22] P. Fisk, Creative Genius: An Innovation Guide for Business Leaders, Border Crossers and Game Changers, West Sussex, United Kingdom: Capstone Publishing Ltd., 2011.

[23] Stanford University, "Stanford 2025," [Online]. Available: http://www.stanford2025.com/ \#intro. [Accessed 154 2016].

[24] C. Fredman, "The Ideo Difference," Hemispheres, August 2002.

[25] R. Sagor, Guiding School Improvement with Action Research, Alexandria, VA: ACSD, 2000 .

\section{Authors}

B. LaDuca is with the Institute of Applied Creativity for Transformation at ArtStreet, University of Dayton, Dayton, OH 45469, USA (bladuca1@udayton.edu).

A. Ausdenmoore is with the Institute of Applied Creativity for Transformation at ArtStreet, University of Dayton, Dayton, OH 45469 USA (aausdenmoore1@udayton.edu).

J. Katz-Buonconintro is with the School of Education, Drexel University, Philadelphia, PA 19104 (jkb@drexel.edu).

K. P. Hallinan is with the Department of Mechanical and Aerospace Engineering, University of Dayton, Dayton, OH 45419 USA (kevin.hallinan@udayotn.edu).

K. L. Marshall is with the Institute of Applied Creativity for Transformation at ArtStreet, University of Dayton, Dayton, OH 45469 USA (kmarshall2@udayton.edu). 